\title{
The prospects of the use of thin-film heat-insulation coatings for the protection of the pipelines of heating systems and power equipment
}

\author{
A. V. Volkov, N. A. Loginova \& A. F. Pristshepov \\ Scientific Research Center "Wear Resistance", \\ National Research University "Moscow Power Engineering Institute", \\ Russian Federation
}

\begin{abstract}
Heat loss in the heat supply systems of the Russian Federation reaches 300 million Gcal a year during transport. Excess heat loss is mostly due to the poor condition of the thermal insulation assemblies of pipelines and power equipment. Modern requirements for heat insulation coatings stipulate that they possess low thermal conductivity values, high mechanical properties, resistance to alternating loads and a vibration. The dynamics of market growth for thin-film heat-insulation coatings is positive today. Thin-film heat-insulation coatings are created by using hollow microspheres and various binders. Opinions of experts about the efficiency of their use differ. Generally, this is due to little research on thin-film heatinsulation coatings. Tests were conducted to determine the effects of various kinds of microspheres and binders on the mechanical and thermal characteristics of thin-film heat-insulation coatings. This was done to understand the efficiency of the use of thin-film heat-insulation coatings for heating systems and power equipment. During the testing of thin-film thermal insulation coatings, the conditions were simulated to be the same as the real operating conditions of pipeline heating systems and power equipment. The test results show the efficiency of thin-film heat-insulation coatings on the base of hollow glass microspheres and polymer binders. The use of such kinds of thin-film heatinsulation coatings allows for the reduction of heat loss from the surfaces of the pipelines and power equipment, which improves the mechanical properties of the coatings in comparison to the use of traditional materials.

Keywords: heat supply, heat insulation, heat networks, pipelines, heat conductivity coefficient, thin-film heat-insulation coatings, adhesion.
\end{abstract}




\section{Introduction}

Energy saving is one of the most important tasks today. It is connected to the rational use and conservation of the natural resources of our planet. The relevance of this problem is most brightly expressed in relation to the Russian Federation. The average ambient temperature for the country is $-5.5^{\circ} \mathrm{C}$. The length of the heat supply systems of the Russian Federation is $176,000 \mathrm{~km}$, according to official figures. About $45,000 \mathrm{~km}$ of this quantity are in an accident condition [1]. The heat loss during transport reaches 300 million Gcal a year. The general expenses of a heat supply amount to about 2000 million Gcal a year [2]. The annual losses of energy resources in our country are comparable to the annual power consumption of industrially developed European states.

The process of district heating is widely developed in the Russian Federation. This process consists of three sequential steps: preparation, transport and the use of the heat carrier [3]. Each of the above operations is accompanied by the non-productive losses of energy. A decrease in such losses is an important function of energy saving.

\section{Current state of the heat-insulation constructions of pipelines and equipment for systems of a heat supply}

Actual heat losses in domestic heat supply systems for the transport of thermal energy is up to $30 \%$ and above [4]. The quality of thermal insulation has a significant impact on the quantity of heat loss experienced in the large length of the pipelines of heat supply systems. Heat losses from the backbone heat supply networks and from the distributive heat supply networks are significantly different. The technical conditions of the backbone networks are generally much better. The total surface area of the backbone networks is much less than that of the distributive networks. This is due to the big branching and length of the distributive networks. So the heat losses from the backbone networks are several times less than that of the distributive networks [5].

Low-quality insulation is one of the main causes of the damage of pipe and heat transfer surfaces. As soon as cracks are formed the heat carrier is lost. Damage to the pipelines of heat networks are mostly due to external corrosion (up to $80 \%$ of cases). This corrosion is due to the contact made between the metal surfaces of pipes and water, in the form of periodic or permanent ground water and aboveground water flooding of the channels. More than $85 \%$ of the total length of heat networks are underground pipelines in the passable and impassable channels in the Russian Federation. The mineral wool is generally used as a heat insulation material.

Modern requirements for heat insulation coatings are characterized by low heat conductivity value, high mechanical properties, resistance to alternating loads and a vibration [6]. 


\section{Analysis of the commonly used types of heat insulation materials for heat supply systems}

As a rule, fibrous materials are used as heat insulation for pipeline constructions in the channels. For example, mineral wool and glass fibers are used, which take the form of the mats and cylinders. More than $90 \%$ of all domestic pipelines of the heat supply systems use heat insulation constructions made with mineral wool. A significant drawback of such heat insulation materials is their hygroscopicity. The heat losses experienced through the surfaces of the wet heat insulation are increased by several times and corrosion processes are intensified. The resources of the pipelines of heating networks that use such a kind of insulation are exhausted in 5-7 years of their operation.

Pipes with factory heat-insulation and waterproofing are used for the underground pipelines of heat networks in channels. The waterproof coating eliminates the possibility of moisture in the insulation during operation. The reinforced foam concrete, polyurethane foam, and polymer concrete are recommended for use as the main heat-insulation layer of heat insulation without-channel constructions.

The advantages of heat pipes with polyurethane foam insulation include their low heat conductivity coefficient values $(0.03-0.05 \mathrm{Wt} /(\mathrm{mK}))$, their manufacturability during the manufacture and installation of heat pipes, and their durability if the requirements of the installation and operation are complied. But the operating temperature of polyurethane foam ranges from 110 to $130^{\circ} \mathrm{C}$ according to various data. A positive example for the use of polyurethane insulation is given by the countries of Western Europe. The temperature of the heat carrier is $100^{\circ} \mathrm{C}$ in Western Europe countries. Pipelines with polyurethane heat insulation have been operated for 30-50 years there. The soil temperature is negative in winter for most regions of Russia; the temperature of the heat carrier reaches $150^{\circ} \mathrm{C}$. The polyurethane foam heat insulation of without-channel constructions rapidly loses its resource.

The advantages of heat pipes with reinforced foam concrete are non-combustibility, the high temperature limit of its application (up to $300^{\circ} \mathrm{C}$ ), an absence of corrosion of steel pipes, and durability. The positive experience of reinforced foam concrete insulation can be seen in several regions of the Russian Federation. But the value of the heat conductivity coefficient of the dry reinforced foam concrete is $0.08 \mathrm{Wt} /(\mathrm{mK})$. This value is two times more than it is for the polyurethane foam insulation. The value of the heat conductivity coefficient of the reinforced foam concrete is increased by 1.55 times, if the humidity is $12 \%$ by mass (or $4.2 \%$ by volume) [7]. But it should be noted that the surface of the reinforced foam concrete is hydrophilic. The reinforced foam concrete is humidified during contact with the damp soil. Therefore, the thermal insulation properties of this material decrease during operation.

The temperature limit for the application of the polymer concrete is up to $150^{\circ} \mathrm{C}$. However its thermal insulation properties are worse than those of the polyurethane foam insulation. Polymer concrete is not widely used. The production volumes of the polymer concrete are limited. 
New kinds of heat insulation materials are now available in the market for heat insulation. These materials are created by using hollow microspheres and various binders. It is thin-film heat-insulation coatings (THIC). The values of the heat conductivity coefficient in the technical specifications and instructions for use of the THIC fluctuate are in the range of 0.001 to $0.450 \mathrm{~W} /(\mathrm{mK})$. There is no longterm experience in the operation of THIC in the pipelines of heat supply systems and power engineering equipment.

The characteristics of the main physicomechanical and operational properties of the commonly used types of heat insulation materials for heat supply systems are shown in table 1 .

Table 1: The main physicomechanical and operational properties of the commonly used types of heat insulation materials for the systems of a heat supply $[6,8]$.

\begin{tabular}{|l|c|c|c|c|}
\hline Type of material & $\begin{array}{c}\text { Density } \\
\text { apparent } \\
\text { density) } \\
\mathrm{kg} / \mathrm{m}^{3}\end{array}$ & $\begin{array}{c}\text { Heat conductivity } \\
\text { coefficient value, } \\
\mathrm{W} /(\mathrm{mK}), \text { at 293 K }\end{array}$ & $\begin{array}{c}\text { Temperature } \\
\text { limit of } \\
\text { application, }{ }^{\circ} \mathrm{C}\end{array}$ & $\begin{array}{c}\text { Compressive } \\
\text { strength, } \mathrm{MPa}\end{array}$ \\
\hline Mineral wool & $34-350$ & $0.033-0.058$ & $300-700$ & $0.001-0.015$ \\
\hline $\begin{array}{l}\text { Glass wool and } \\
\text { fiberglass }\end{array}$ & $13-140$ & $0.010-0.045$ & 400 & $0.030-0.061$ \\
\hline Polymer concrete & 400 & 0.07 & 150 & 0.8 \\
\hline $\begin{array}{l}\text { Polyurethane } \\
\text { foam }\end{array}$ & $50-100$ & $0.033-0.05$ & $110-130$ & $0.1-0.22$ \\
\hline $\begin{array}{l}\text { Reinforced foam } \\
\text { concrete }\end{array}$ & $350-450$ & $0.08-0.16$ & 300 & $1.0-2.5$ \\
\hline
\end{tabular}

\section{Description of THIC tests}

To solve the real problem with the efficiency of using THIC for heat supply systems and power equipment the tests were performed in NRU "MPEI". The tests were performed to determine the influence of various kinds of microspheres and binders on the mechanical and thermal characteristics of coatings [9].

The adhesion of microspheres in the coatings matrix and to the metal surfaces is dependent on the quality of the binding substances and as a consequence, on the durability of the coatings as well. The adhesion tests of THIC were conducted in NRU "MPEI". The samples of THIC were prepared using non-water-soluble anticorrosive binders. The binders recommended for the use in pipelines and the equipment of heat and water supply systems were: organic silicon, epoxy, and organic silicate. The adhesion strength of THIC was determined by the method of normal separation. The effort that was necessary for coat separation from a substrate was measured. This was performed using an adhesimeter, with the application of hydraulic loading. The adhesive strength of the samples of THIC on the basis of the organic silicate binder was not measured due to the fragility and low strength of the coating. The adhesion values of the samples of THIC on the 
basis of organic silicon and epoxy binders and steel surfaces differed substantially and were $1 \mathrm{MPa}$ and $3 \mathrm{MPa}$ respectively.

The comparison of the adhesion strength of the samples of THIC on the basis of organic silicon $\left(\mathrm{THIC}_{\mathrm{OS}}\right)$ and epoxy $\left(\mathrm{THIC}_{\mathrm{E}}\right)$ binders, polymer concrete $(\mathrm{PC})$ and polyurethane foam (PF) and steel surface is shown in fig. 1.

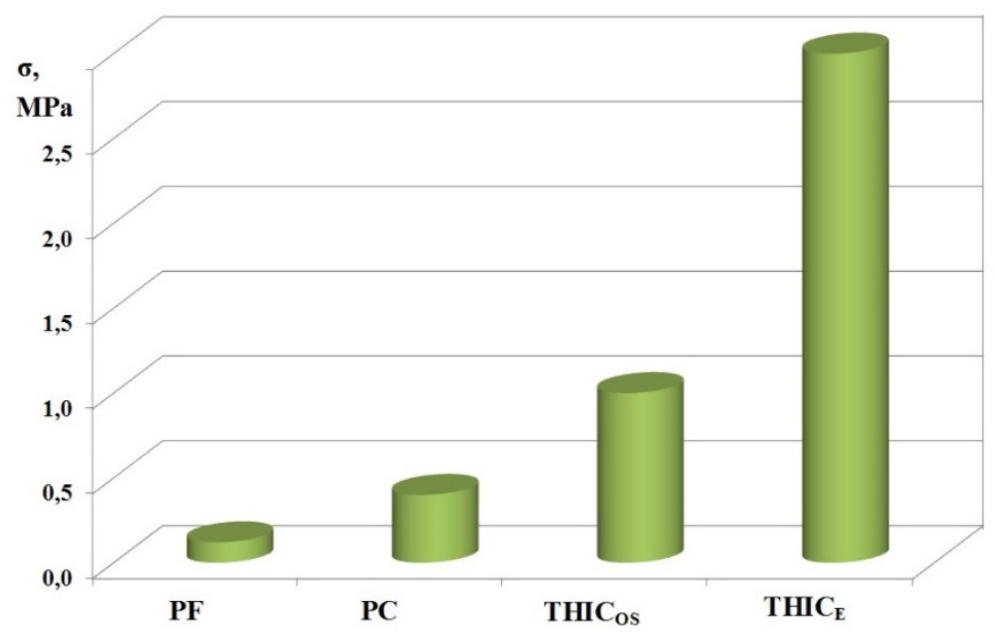

Figure 1: Comparison of the adhesion strength of the samples of different kinds of the heat insulation and a steel surface.

The adhesion strength of the samples of THIC on the basis of organic silicon and epoxy binders and a steel surface is much higher than the adhesion strength of the samples of the commonly used types of heat insulation. This indicates the efficiency of the use of THIC for the insulation of pipelines and equipment of heat networks of heat supply systems and increases their durability.

Patent database analysis was performed before testing the microspheres. Results found that cenospheres and hollow glass microspheres were used during the manufacturing of THIC. Cenospheres contain nitrogen and carbon dioxide. This is a result of the process of burning coal in thermal power plants. Hollow glass microspheres are produced using industrial methods for melting glass. Such kinds of microspheres are filled with rarefied air.

These two types of microspheres were selected for THIC testing. The samples of THIC were applied to the surface of the cylindrical steel basis. A distribution of values of temperature on the surface of the THIC was determined during the test. Temperature set points of the cylindrical steel basis surface was maintained using an electric heater in the range of $+50^{\circ} \mathrm{C}$ to $+120^{\circ} \mathrm{C}$. Temperature control was carried out with the help of an electronic regulator. The specified temperature range is typical for heat supply systems. Furthermore, formula (1) was used to determine the heat conductivity coefficient. This formula is developed for a cylindrical wall and is derived from the Fourier equation of heat conduction [10]. 
where:

$$
\lambda=\frac{q r_{1} \ln \frac{r_{2}}{r_{1}}}{T_{1}-T_{2}}
$$

$\mathrm{r}_{1}, \mathrm{r}_{2}$ - the radius of the cylindrical steel basis and of the surface of THIC, respectively, $\mathrm{m}$;

$\mathrm{q}-\mathrm{a}$ heat flow density, $\mathrm{W} / \mathrm{m}^{2}$;

$\mathrm{T}_{1}, \mathrm{~T}_{2}$ - the values of temperature on the cylindrical steel basis and on the surface of THIC, K.

In particular, the value of the heat conductivity coefficient of the single-layer THIC was $0.022 \mathrm{~W} /(\mathrm{m} \cdot \mathrm{K})$ at $60^{\circ} \mathrm{C}$ and $0.030 \mathrm{~W} /(\mathrm{m} \cdot \mathrm{K})$ at $100^{\circ} \mathrm{C}$ for the samples with the hollow glass microspheres and $0.14 \mathrm{~W} /(\mathrm{m} \cdot \mathrm{K})$ and $0.18 \mathrm{~W} /(\mathrm{m} \cdot \mathrm{K})$ for the samples with cenospheres in similar conditions. The test results are shown in fig. 2. The value of the heat conductivity coefficient of the samples of THIC with cenospheres was by one order of magnitude greater than that of the samples of THIC with hollow glass microspheres.

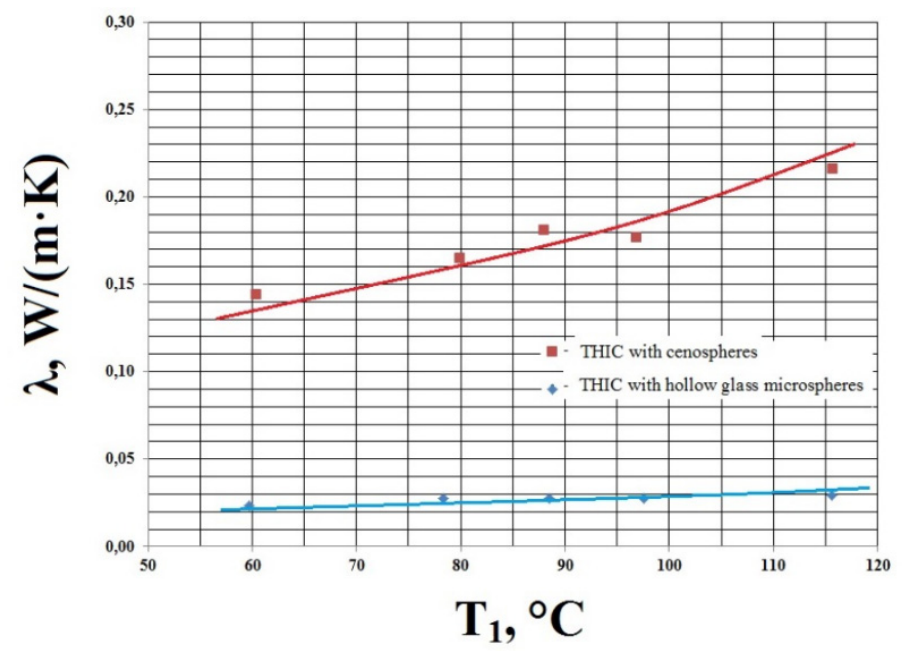

Figure 2: The Influence of the temperature on the heat conductivity coefficient of a single-layer THIC when cenospheres and hollow glass microspheres are used.

\section{Conclusions}

The test results showed the efficiency of thin-film heat-insulation coatings, which are based on hollow glass microspheres and polymeric binders. The use of such kinds of thin-film heat-insulation coatings allows for the reduction of heat loss from the surfaces of the pipelines and power equipment, improving the mechanical properties of the coatings by comparison to traditional materials. All this makes the use of thin-film heat-insulation coatings very promising, but additional research is required. 


\section{Acknowledgements}

The work was carried out with the financial support of the Ministry of Education and Science of the Russian Federation in the framework of Agreement №14.574.21.0069 from 06/27/2014.

\section{References}

[1] Nekrasov A.S., Sinjak Y.V., Voronina S.A. The current state of Russian heat supply systems. Problems of Forecasting, 1, pp. 30-42, 2011.

[2] Bashmakov I.A. Energy saving potential in Russia. Energy saving, 1, pp. 28-35, 2009.

[3] Sokolov E.Y. District heating and heat networks. Textbook for universities, MPEI, Moscow, 2009.

[4] Ryzhenkov A.V. \& Suhova E.A. Reduction of the hydraulic resistance of pipeline systems. Power engineer, 1, pp. 42-44, 2012.

[5] Livchak V.I. Improving the district heating systems of large cities in Russia, AVOK, 5, pp. 42-49, 2004.

[6] Kochergin S.M. Insulation. Materials, structures, technologies. A Reference Guide. Strojinform, Moscow, pp. 10-13, 2008.

[7] Valgin V.D. Domestic energy technology insulation of building structures using a new generation of foam. Plastics, 10, pp. 44-48, 2007.

[8] Mikulskij V.G., Kozlov V.V. Building materials. Publisher Association of building high schools, Moscow, 2004.

[9] Ryzhenkov V.A., Pristshepov A.F., Loginova N.A., Kondratjev A.P. The influence of microspheres and binder on the heat conductivity of thin-film insulating coatings. Reliability and safety of energy, 3(10), pp. 28-30, 2010.

[10] Tsvetkov F.F., Grigorjev B.A. Heat and mass transfer. Textbook for universities. MPEI, Moscow, 2001. 